\title{
SENTIDOS HISTÓRICOS Y POSICIONES CONTEMPORÁNEAS DE LA ENSEÑANZA DE LA DANZA EN LA ESCUELA ARGENTINA
}

\author{
SENTIDOS HISTÓRICOS E POSICÕES CONTEMPORÂNEAS NA EDUCAÇ̃O EM DANCA NA \\ ESCOLA ARGENTINA
}

Lucía Merlos $^{1}$

http://dx.doi.org/10.52641/cadcaj.v6i4.541

RESUMEN: Retomando la exposición realizada en el marco del IV Simpósio nacional y el I Simpósio internacional de Infância, Educação e Teoría Crítica, en octubre del 2020, y alojando inquietudes por la educación, este artículo desarrolla el lugar de la Danza como contenido escolar en el contexto argentino, específicamente en la provincia de Buenos Aires. De este modo se recorren dimensiones histórico-educativas de la Danza en diferentes prescripciones curriculares (1983-1999), se contextualizan e indagan perspectivas educativas contemporáneas (2008, y 2018), y se evidencia el impacto que tuvo el contexto de COVID-19 en una educación virtualizada de la Danza. Desde un enfoque cualitativo, se construye un relato a partir del rastreo, el mapeo y el análisis de documentos oficiales, como leyes educativas, disposiciones y lineamentos curriculares, bajo la concepción etnográfica de los documentos como campo, reconociéndolos como parte de un campo de indagación en sí mismo que requiere ser contextualizado y no como meros datos (Muzzopapa E., Villalta C., 2011). Perspectiva que se ve complementada con la información obtenida a partir de entrevistas realizadas a especialistas en el campo de la danza y la escuela. Interesa entender las tramas entre lo normativo y los contextos históricos, tanto como entre las consideraciones educativas y las prácticas de enseñanza.

Palabras claves: Danza, Escuela, Provincia de Buenos Aires.

RESUMO: Retornando à exposição realizada no âmbito do IV Simpósio Nacional e do I Simpósio Internacional de Infância, Educação e Teoría Crítica, em outubro de 2020, e acolhendo preocupações pela educação, este artigo desenvolve o lugar da Dança como conteúdo escolar no contexto argentino, especificamente na província de Buenos Aires. Desse modo, as dimensões histórico-educacionais da Dança são contempladas em diferentes prescrições curriculares (19831999), as perspectivas educacionais contemporâneas são contextualizadas e investigadas (2008 e 2018), e o impacto que o contexto do COVID-19 teve em um ambiente virtualizado educação da dança. A partir de uma abordagem qualitativa, uma história é construída a partir do rastreamento, mapeamento e análise de documentos oficiais, como legislações educacionais, dispositivos e diretrizes curriculares, sob a concepção etnográfica do documento como um campo, reconhecendo-o como parte de um campo de investigação em si que precisa ser contextualizado e não como meros dados (Muzzopapa E., Villalta C., 2011). Esta perspectiva é complementada pelas informações obtidas em entrevistas com especialistas da área da dança e da escola. É

\footnotetext{
1 Educadora e investigadora en formación. Profesora de Arte en Danza (IPA). Licenciada en Arte (UNSAM). Magister en Educación Corporal (UNLP), Doctoranda en la Universidad de Buenos Aires. Becaria interna doctoral por el CONICET.
} 
interessante compreender as teias entre os contextos normativo e histórico, bem como entre as considerações educacionais e as práticas de ensino.

Palavras-chave: Dança, Escola, Província de Buenos Aires

ABSTRACT: Returning to the exhibition held within the framework of the IV National Symposium and the I International Symposium of Infância, Educação e Teoría Crítica, in October 2020, and hosting concerns for education, this article develops the place of Dance as school content in the context Argentine, specifically in the province of Buenos Aires. In this way, historical-educational dimensions of Dance are covered in different curricular prescriptions (1983-1999), contemporary educational perspectives are contextualized and investigated (2008, and 2018), and the impact that the context of COVID-19 had on a virtualized education of Dance. From a qualitative approach, a story is built from the tracking, mapping and analysis of official documents, such as educational laws, provisions and curricular guidelines, under the ethnographic conception of documents as a field, recognizing them as part of a field of inquiry in itself that needs to be contextualized and not as mere data (Muzzopapa E., Villalta C., 2011). This perspective is complemented by the information obtained from interviews with specialists in the field of dance and school. It is interesting to understand the webs between the normative and historical contexts, as well as between educational considerations and teaching practices.

Key-words: Dance, School, Province of Buenos Aires.

\section{INTRODUCION}

En el contexto del IV Simpósio nacional e I Simpósio internacional de Infância, Educaşão e Teoría Crítica, llevado a cabo en el mes de octubre del año 2020, y en relación a la pregunta por la educación de las infancias, este artículo retoma parte de una línea de investigación precedente sobre el lugar de la Danza en la escolaridad argentina, específicamente en la provincia de Buenos Aires, articulando y profundizando perspectivas educativas contemporáneas en dialogo con posiciones de educadores y educadoras sobre los sentidos de la enseñanza de la Danza y el impacto del COVID-19 en la práctica educativa.

Un estructura organizada a partir de tres grandes preguntas: ¿Qué recorridos históricos pueden visibilizarse en la inclusión de la disciplina Danza en la escolaridad de la provincia de Buenos Aires?, ¿Qué contenidos educativos priorizan las perspectivas curriculares contemporáneas?, y ¿Qué devela su enseñanza en un contexto de COVID 19?, que funcionan como ejes ordenadores. 
De este modo, se presentan dimensiones histórico-educativas de la Danza en la escuela, se despliegan y profundizan perspectivas contemporáneas de su educación -desde marcos legislativos actuales y desde dos diseños curriculares de los años 2008 y de 2018-, y se retoman a partir de diálogos establecidos recientemente con educadoras y educadores, sentidos de su enseñanza, visibilizando también las principales transformaciones durante el año 2020 en el contexto de Aislamiento Social Preventivo y Obligatorio (ASPO) ${ }^{2}$.

Si bien los caminos para investigar el lugar de la danza en la escolaridad pueden ser diversos, este trabajo se detiene en el desarrollo de perspectivas curriculares, describiendo las diferentes prescripciones educativas de la Danza como contenido de educación estética y de educación artística, entre finales del siglo XX y principios del siglo XX.

Retomando investigaciones previas (Merlos, 2020) se incluye un relato construido a partir del rastreo, mapeo y análisis de documentos oficiales, como leyes educativas, lineamientos y lineamientos curriculares, desde una concepción etnográfica de los documentos. Entendiéndolos como campo se los reconoce "antes que como meros datos o variables independientes, como parte de un campo de indagación a partir del cual se pueden delinear sendas de investigación que permitan, mediante una completa contextualización, explorar los sentidos con los que fueron dotados" (MUZZOPAPA E., VILLALTA C., 2011, p. 38). Y de entrevistas realizadas a diferentes especialistas en el campo de la danza y la escuela en el marco de la tesis de Maestría DANZA Y ESCUELA. Perspectivas educativas en la provincia (MERLOS, 2020).

Por su parte este artículo incluye las voces de educadoras y educadores de Danza, que se trabajan en el nivel inicial y en el nivel primario, para poner en diálogo las perspectivas prescriptivas y las prácticas escolares.

Resulta difícil establecer desde cuándo hay danza en la escolaridad bonaerense, dado que su presencia, que recorre gran parte de la segunda mitad del siglo XX, y que dialoga con la institucionalización del campo de las danzas folklóricas argentinas (BLACHE 2007, HIROSE 2010), ha tenido objetivos y modalidades diversas.

Se ha enseñado danza, por mencionar solo algunas de sus modalidades dentro de la escuela: desde una mirada folklórica como parte de la cultura escolar con especial acento en la transmisión de contenidos identitarios y nacionalistas; como un modo de educación del cuerpo y de corporalidades; como espacio de expresión subjetiva; como momento recreativo; como

\footnotetext{
2 Medida adoptada por el gobierno argentino que implicaba que las personas permanecieran en sus domicilios habituales pudiendo realizar desplazamientos mínimos "con el fin de proteger la salud pública frente a la propagación del nuevo coronavirus” https://www.argentina.gob.ar/coronavirus/aislamiento.
} 
práctica extracurricular impartida en talleres; tanto como en espacio curricular especialmente destinado a ello.

Sin embargo, siguiendo la ruta de los documentos y los relatos de especialistas, como resultado de la investigación ya mencionada, y presentada como tesis de Maestría en Educación Corporal, fue posible organizar un discurso oficial sobre consideraciones educativas de la Danza entre 1983 y 2018.

Retomando esta línea este artículo presenta y desarrolla a grandes rasgos, cuatro grandes momentos curriculares, bajo las denominaciones de: la Danza desde lo Foklórico (1983, 1993), la Danza desde la perspectiva de la Danza Expresión Corporal (1995, 1999), la Danza como campo campo especifico de conocimiento y derecho a la cultura (2008), y la Danza disciplina/lenguaje desde una perspectiva cognitivista del campo artístico (2018) ${ }^{3}$.

Instancias que se superponen, dialogan y que no pueden ser pensadas como directrices que impactan directamente en la enseñanza, sino como grandes marcos teóricos que contienen y desarrollan una orientación sobre qué enseñar y para qué dentro de políticas educativas provinciales específicas.

Se desarrolla entonces, en primer lugar la perspectiva de la Danza desde lo Folklórico (1983, 1993) y de la Danza desde la perspectiva de la Danza Expresión Corporal (1995, 1999), dejando para un segundo momento la reflexión sobre las concepciones contemporáneas de su enseñanza, a partir de las reflexiones sobre la Danza como campo especifico de conocimiento y derecho a la cultura (2008), y la Danza disciplina/ lenguaje desde una perspectiva cognitivista del campo artístico (2018). Abordando en última instancia, como trazo inicial y provisorio, reflexiones sobre la enseñanza de la Danza en general y particularmente durante el año 2020 a diálogos establecidos con educadoras y educadores.

\section{DESENVOLVIMENTO}

\subsection{Devenires históricos de la Danza en la escolaridad bonaerense}

La Danza ha sido parte del cotidiano escolar como práctica transmitida por maestras/os de grado; por profesoras/res de música; por profesoras/profesores de educación física; tanto como por madre/padre/o familiar que supiera bailar y se propusiera para enseñar determinada

\footnotetext{
3 Denominaciones que sintetizan las líneas más importantes de cada momento curricular construido en el
} marco de la tesis de maestría citada.

Cadernos Cajuína, v. 6, n. 4, 2021, p. 156-179. 
danza para alguna ocasión especiales, la escenificación y/o representación coreográfica en actos patrios.

Sin embargo es a partir de 1983 que egresadas y egresados de las escuelas superiores de formación artística, especialmente en Danzas Tradicionales Argentinas de la provincia, podrán ingresar al sistema educativo formal inaugurando un espacio curricular a cargo de especialistas en danza.

De este modo, y a partir de reconocer tal como se anticipó cuatro grandes momentos curriculares entre 1983 y 2018, este apartado se detiene específicamente en la inclusión de la Danza desde la perspectiva folklórica (1983-1993), y desde la perspectiva de la Danza Expresión corporal (1995-1999). Dejando los lineamientos curriculares de principios del siglo XX para el análisis de los enfoques contemporáneos de su enseñanza.

\subsubsection{Danza desde lo Folklórico $(1983,1993)$}

Tomar como referencia el año 1983 es construir el relato a partir de las voces de los protagonistas de un campo, dado que dicha fecha marca el inicio del ingreso de educadoras y educadores en Danza, especialmente en Danzas Tradicionales Argentinas, para su desempeño en el nivel primario provincial.

La Danza desde lo Folklórico, es la denominación bajo la cual, en el marco de este artículo, se desarrolla la inclusión de la Danza desde una perspectiva folklórica en la escuela primaria, desplegada principalmente a partir del ingreso de especialistas en la escuela (1983) y del uso de dos diseños curriculares: uno general el documento Lineamientos curriculares Educación Básica de $1^{\circ}$ a $7^{\circ}$ grado de 1986, y un diseño específico para el área, que circulo en principio en la ciudad de La Plata, capital de la provincia, el Anexo I, disposición N³1: Diseño curricular de Danz̧a (y Folklore) de 1993.

Si bien puede reconocerse que cada documento curricular tendrá su particularidad, identificamos el lugar de la danza como expresión artística y cultural junto con otras expresiones folklóricas como: la literatura folklórica, la música regional, los instrumentos, las artesanías locales, los modos de vida actuales y del pasado, las costumbres, la geografía, y las formas de organización socio-económicas de las poblaciones. 
En el uso del Diseño curricular de educación básica de $1^{\circ}$ a $7^{\circ}$ grado, la enseñanza de la Danza desde lo folklórico se vinculaba mayormente, según los entrevistados, con el Eje Dinámico, el Eje Estético y el Eje Intelectual, a partir de contenidos como:

Conocer las posibilidades de movimiento de todas las partes del cuerpo; usar su cuerpo global y segmentariamente en actividades o juego; tomar conciencia del eje corporal; dominar el equilibrio corporal en situaciones estáticas y dinámicas (Eje Dinámico).

Creación libre utilizando distintos lenguajes expresivo; actividades creativas para el disfrute del tiempo libre; la difusión de la cultura popular; participación y vivencia de manifestaciones artísticas culturales y con sensibilidad estética (Eje Estético)

Tanto como su relación con la enseñanza de cuentos, leyendas y literatura folklórica, y contenidos referidos al desarrollo de la cultura local y rural (Eje intelectual).

Por otro lado, el acceso fundamental al relato de quienes trabajaban en la escuela entre fines de la década del '80 y mediados de la década del '90 motorizo la búsqueda de un documento curricular específico, que según docentes era acercado a los docentes mediante inspectoras de artística, dicho documento es el Anexo I, disposición $N^{\circ} 31$, Diseño curricular especifico de Danza (Folklore), es un diseño curricular específico que entendemos retoma y sistematiza sentidos que hasta ese entonces circulaban sobre lo que debía enseñar en danza y folklóre.

Presentado como un documento que responde a "la necesidad de producir una guía orientadora del área de Folklore, dentro de la Educación Básica (nivel primario)” y que entiende a la escuela como "el terreno más fértil para convertirse en centro de divulgador de conocimientos del auténtico Folklore" (Disposición N³1, 1993, p. 1). Prescribe y desarrolla el campo de lo folklórico -y dentro de este a las diferentes danzas folklóricas argentinas-, como posibilidad de expresión y apropiación de lo propio y lo regional, priorizando la valorización y la difusión de la cultura argentina.

Por su parte la dimensión de la educación del cuerpo y de lo corporal se presenta en la participación y aprendizaje de juegos tradicionales y rondas; en una educación del movimiento asociada a las formas básicas de locomoción, relaciones de tiempo y espacio, calidades de movimiento; tanto como el aprendizaje de diferentes las danzas tradicionales, su expresión, ubicación espacial, ejecución de pasos, figuras, elementos accesorios y elementos coreográficos. Danzas como: Carnavalito, Pericón, Danza de las Cintas, Gato, Gato Cuyano, Calandria, 
Caramba, Chacarera, Chacarera Doble, Pajarito, Escondido, Remedio, Triunfo, Huella, Mariquita, Amores, Cuando, entre otras.

Un primer momento curricular que anida de este modo un abordaje técnico, expresivo y contextual de las diferentes danzas, desde la valoración y el reconocimiento de lo propio, lo folklórico, como representante de una cultura nacional, donde la escuela tiene un lugar central.

\subsubsection{Danza desde la perspectiva de la Danza Expresión Corporal}

En el marco de la Ley Federal de Educación N² 24.195 de 1993 y la Ley Provincial de Educación Nº11.612 de 1994, el contenido educativo Danza se incorpora dentro de los lineamientos curriculares como un lenguaje artístico bajo la denominación de Expresión Corporal.

Tomando como referencia los diferentes documentos producidos por la Dirección General de Cultura y Educación de la provincia de Buenos Aires, entre los años 1995-1999, se retoman en este artículo las principales consideraciones que evidencian objetivos, contenidos y propósitos de la Danza dentro del área de Educación Artística.

Si bien pueden reconocerse tres grupos de documentos curriculares: los Módulos (del 0 al 8) destinados a docentes y escuelas bonaerenses en el año 1995; los Documentos Curriculares de los años 1996-1997; un Marco General, el Tomo I y Tomo II del Diseño curricular para la Educación InicialEducación General Básica del año 1999, en este caso se indaga centralmente el contenido del último documento, el Tomo II, como síntesis de un proceso curricular.

Lo primero a considerar aquí es la íntima relación establecida con el marco educativo nacional y el impacto que la elaboración de los Contenidos Básicos Comunes (CBC), como matriz de contenidos a nivel nacional, que tienen en la provincia de Buenos Aires.

Dentro de los CBC se presenta a la Educación Artística como área conformada por lenguajes artísticos: Música, Plástica, Teatro, Expresión Corporal, Danza y Folklore, especificando que "cada uno de estos lenguajes, a partir de códigos que le son propios, se incorporan al área Artística, como disciplinas autónomas con contenidos específicos" (MODULO 0, 1995, p. 201).

Instancia dentro de la cual el concepto de lenguaje tiene un gran impacto en la configuración de la educación de las artes, con continuidad y ampliación de sentido en perspectivas posteriores. 
Sobre esta línea Daniel Belinche sostiene que "en los '90, el eco tardío de una versión degradada de la semiótica- que incidió en la redacción de los Contenidos Básicos Comunesreorientó la educación artística hacia la búsqueda de su estructura gramatical” (2011, p. 10). Lo que significa que en este período se articula, dentro de las fundamentaciones de la Educación Artística escolar, el concepto de lenguaje proveniente del campo de la semiótica, en un discurso hacia la alfabetización en los lenguajes artísticos.

Los textos curriculares refuerzan la consideración de Lenguaje/Expresión dentro del área, en tanto que encierran procesos, contenidos específicos, construcción de mensaje o reinterpretación, en contrapartida a una consideración de apoyo o medio para el aprendizaje de otras áreas o actividades. Desarrollo que permite identificar un posicionamiento que busca independizar saberes específicos del campo del arte en la educación de otros campos de conocimiento, y de otras asignaturas, fundamentando y explicitando consideraciones teóricas y curriculares particularizadas. Es decir, distanciándose de una consideración complementaria del arte dentro de la escuela, sosteniendo que:

La música, la plástica, la expresión corporal y el teatro pueden ser sólidamente
fundamentados como área en el proceso educativo del niño desde múltiples perspectivas:
las psicológicas, dado los procesos interactivos y afectivos que se movilizan para pintar,
actual, cantar y expresarse corporalmente, las psicomotrices, dado que se integran todas
las dimensiones del sujeto en el acto de expresión; las sociológicas, por la interrelación de
sujetos en pos de la realización de una producción común, considerando su significación
como rito social; las antropológicas, que implican las resonancias de la historia de la
cultura del hombre implícitas en todo hecho artístico; y por último, la culturales, en tanto
producto de la cultura humana, en particular de los grupos en los cuales está inserto el
sujeto en su relación con la historia y con la identidad cultural de su comunicad
(MODULO,1995, p. 202).

Por su parte en los lineamientos provinciales podemos reconocer la presencia de cuatro lenguajes artísticos: Plástica-Visual, Música, Teatro, y Danza Expresión Corporal. Donde la enseñanza lo corporal y del movimiento en relación a la Danza se inscribe como Danza Expresión Corporal, especialmente en lo que refiere a los contenidos educativos y la línea pedagógica.

Si bien los contenidos a enseñar de los diferentes lenguajes artísticos, se prescriben a partir de ejes: Lenguaje, Producción, Recepción, Contexto Sociocultural, Campo Tecnológico y Formación Ética. Según consta en el documento, se espera una interrelación dinámica de los contenidos de cada eje, en tanto que: "La comprensión de los elementos de los lenguajes se evidencia en el proceder. El hecho artístico se encuentra inmerso en un contexto, en una cultura; resulta, entonces, indispensable ese vínculo. Dicho de otro modo: los ejes atraviesan las 
disciplinas artísticas y de ningún modo son autosuficientes" (DISEÑO CURRICULAR Tomo II, 1999, p. 109).

De este modo dentro del lenguaje artístico Danza-Expresión Corporal, se prescriben contenidos por grupos:

Conocimiento corporal, formas de locomoción, calidades de movimiento, el cuerpo en el espacio, el movimiento en el tiempo, la comunicación (dentro del eje lenguaje).

Herramientas y procedimientos, referido al cuerpo, sus respuestas de movimiento, el uso de objetos escenoplásticos, la voz, el silencio e imágenes, vinculado a la exploración, improvisación y organización de percepciones, sensaciones y movimientos (eje producción).

Procesos de observación, recepción, comparación, interpretación, y análisis (eje recepción).

Relación del movimiento con el contexto natural y social, reconocimiento diferentes estilos: clásico, folklórico, tango, danzas de pareja. Y el análisis de la producción artística y los medios de comunicación. Reconocimiento del patrimonio cultural y las distintas manifestaciones artísticas (eje del contexto Sociocultural).

Análisis de productos, orientado identificación de estructura y la relación entre los elementos del lenguaje de la danza, los recursos utilizados y la organización del movimiento; y los proyectos: vinculado a las diferentes instancias de la creación de un proyecto artístico, se destaca: identificación de oportunidades, diseño, organización y gestión, la planificación y ejecución, evaluación y perfeccionamiento (eje del campo tecnológico).

Y por último, como contenidos compartidos a todos los lenguajes del área, se especifican contenidos incluidos en subgrupos de: Identidad y autoestima (autoconocimiento y sentido de pertenencia); Autonomía; Valores de convivencia; y conciencia del valor del hábitat (el eje de la formación ética).

A partir de los contenidos indicados para Danza-Expresión Corporal en este período, puede sostenerse que dicha perspectiva establece una sincronía entre la noción de lenguaje artístico, desde la perspectiva político-educativa, y la de lenguaje propio o desarrollo de la propia danza que propone el campo disciplinar de la Expresión Corporal. Disciplina que, al menos 
desde la propuesta de la línea fundadora en Argentina de Patricia Stokoe. "se ha diferenciado de otras concepciones de danza por sus propios objetivos, contenidos, técnicas y metodologías de trabajo que han planteado la posibilidad del desarrollo del lenguaje corporal propio de cada persona" (Kalmar, 2005, p. 28).

De este modo el acento está puesto en la centralidad del cuerpo como productor de sentido dentro de una propuesta general de Educación Artística. Se prioriza la educación del cuerpo y del movimiento desde el reconocimiento sensible, desde la comunicación, la creatividad y la expresión. Se proponen procedimientos como la exploración del movimiento y del espacio, la improvisación, la recepción, la composición, el reconocimiento de diferentes estilos de danzas y sus contextos y producción individual y grupal.

\subsection{Perspectivas contemporáneas de la enseñanza de la danza}

El desarrollo de dos perspectivas curriculares, la del año 2008 y la del 2018, como contemporáneas, se relaciona con el impacto actual que ambas tienen en la escolaridad, por un lado, y que fueron producidas bajo los mismos marcos normativos, a nivel nacional la Ley de Educación Nacional $\mathrm{N}^{\circ} 26.206$ del año 2006, y a nivel provincial la Ley de Educación $\mathrm{N}^{\circ} 13.688$ del año 2007, por otro. Legislaciones que contemplan la presencia del arte y de la Educación Artística en el sistema educativo como campo de conocimiento.

La Ley de Educación Nacional N²6.206 del año 2006 especifica que la Educación Artística en el sistema educativo se comprende, entre otras cosas: la Formación en lenguajes artísticos para niños/as y adolescentes de todos los niveles y modalidades, la modalidad artística orientada de formación específica en el Nivel Secundario, y la formación artística superior impartida en Institutos de Educación Superior (Art. 39). Y suscribe que "Todos/as los/as alumnos/as, en el transcurso de su escolaridad obligatoria, tendrán oportunidad de desarrollar su sensibilidad y su capacidad creativa en, al menos Dos (2) disciplinas artísticas” (Art. 41).

Por su parte a nivel provincial, la Ley de Educación $\mathrm{N}^{\circ} 13.688$ del año 2007, sostiene que "La educación artística es la modalidad que comprende la formación en distintos lenguajes y disciplinas del Arte, entre ellos danza, artes visuales, teatro, música, multimedia, audiovisual y otras que pudieran conformarse, admitiendo en cada caso, distintas especializaciones (...)" (Art.

\footnotetext{
$4 \quad$ Patricia Lulú Stokoe (1919-1996) bailarina, coreógrafa y pedagoga argentina, referente en la creación y difusión de la Expresión Corporal y de la técnica de sensopercepción en Argentina.
}

Cadernos Cajuína, v. 6, n. 4, 2021, p. 156-179. 
37). Dando cuenta en su artículo 38 que "la Educación Artística debe estar a cargo de docentes egresados de Instituciones de Arte de nivel Superior".

Bajo estas primeras consideraciones desarrollamos a la Danza como campo específico de conocimiento y derecho a la cultura (2008) y a la Danza disciplina/ lenguaje desde una perspectiva cognitivista del campo artístico (2018).

\subsubsection{La Danza como campo específico de conocimiento y derecho a la cultura (2008)}

En el marco de un gran reconocimiento a la interculturalidad y de promoción de un acceso igualitario al campo de la cultura desde una perspectiva de derechos, se elaboran el Diseño Curricular para Primer ciclo de la Educación Primaria, y en el Diseño Curricular para Segundo ciclo de la Educación Primaria, ambos del año 2008. En un contexto de valorización de las trayectorias escolares, de la diversidad cultural y de una ciudadanía responsable.

Referido al lugar del arte en la educación sostiene que

El conocimiento artístico-estético constituye un campo de saber humano fundamental para comprender y reflexionar críticamente acerca de nuestra realidad cultural histórico-social y un campo para el desarrollo vocacional y profesional en sus diferentes lenguajes -música, artes visuales, danzas, teatro, multimedia, diseño, audiovisual- con sus distintas especializaciones (DISEÑO CURRICULAR E.P.1, 2008, p. 65).

Subrayando su educación como posibilidad para interpelar e interpretar el mundo desde un campo específico de conocimiento, el campo del arte, donde se enseñe no solo técnicas, recursos, elementos, sino también a expresarse, comunicar, y reconocer la producción de sentido más allá de lo literal (DISEÑO CURRICULAR E.P.1, 2008, p 66). Sosteniendo a su vez una consideración de Educación Artística constituida por cuatro disciplinas: Música, Plástica Visual, Teatro y Danza.

Los contenidos educativos de la Danza en este marco curricular, al igual que los diferentes lenguajes artísticos, se organizan en núcleos temáticos, que varían según el nivel (1er y 2do ciclo) y según la disciplina artística; diferenciándose a su vez dentro de cada núcleo temático cuatro ejes: del Lenguaje, de la Producción, de la Recepción y del Contexto Socio Cultural. Postulando que la Danza debe ser entendida y enseñada desde una selección a partir del reconocimiento de la gran variedad de géneros y estilos que se inscriben, a su vez, en marcos 
socio-históricos y culturales específicos, y de su conceptualización como lenguaje simbólico de carácter metafórico, siendo

\begin{abstract}
Esta dimensión, constitutiva de toda disciplina artística, es lo que aun diferenciándola del lenguaje científico tradicional, la define como una forma particular de conocimiento (...) Así, el presente diseño tiene como objetivo que el aprendizaje de la danza en las escuelas primarias, no quede reducido a que los alumnos y alumnas conozcan las coreografías folclóricas argentinas y latinoamericanas, sino también, a que asocien la danza con lenguaje" (D.C. E.P. 1C, 2008, p. 331).
\end{abstract}

En lo que refiere a la diferenciación de contenidos por ciclos, se prevé en principio un abordaje de los elementos constitutivos del lenguaje corporal (cuerpo, tiempo, espacio, comunicación) en el primer ciclo, y luego las formas de organización del movimiento para "la producción de discursos corporales, propios o preestablecidos y sobre los diferentes contextos socio-culturales que cruzan y determinan la creación" en el segundo ciclo (D.C. E.P 1C, 2008, p.331). Considerando que el conocimiento de los componentes de este lenguaje hará posible la posterior expresión mediante el mismo.

Particularmente se prescriben contenidos a partir de dos núcleos constitutivos: el cuerpo y su registro consciente, y el cuerpo en relación con el espacio, el tiempo, las calidades de movimiento y la comunicación, para el primer ciclo. Y tres núcleos temáticos: El cuerpo en relación con el espacio, el tiempo, las calidades de movimiento y la comunicación y la conciencia corporal; la danza como lenguaje: herramientas y procedimientos de la organización del movimiento; y los discursos corporales y el contexto socio-cultural, para el segundo ciclo.

Tal como se anticipa en la fundamentación, y vuelve a explicitarse en la referencia a los dos núcleos temáticos, para el primer ciclo se proponen contenidos vinculados a reconocer al cuerpo como herramienta expresiva, desde la singularización y la exploración de posibilidades del cuerpo en el espacio, el movimiento, desde el reconocimiento y la interpretación de diferentes estilos de danza, por un lado, y desde la posibilidad de producir discursos corporales, por el otro. Es decir, crear pasos, secuencias de movimiento, diseños espaciales, coreografías desde un lugar del identificación de la danza como práctica cultural contextualizada, tanto como arte, en la posibilidad de generar poéticas propias.

Mientras que, para el segundo ciclo, si bien se recuperan muchos de los contenidos anteriores, el abordaje va desde la exploración y reconocimiento de elementos propios del campo 
de la danza, hacia la complejización disciplinar, la creación y producción escénica, en un marco de reconocimiento de las diferentes identidades culturales que la Danza puede albergar.

La Danza en este contexto curricular evidencia contenidos educativos provenientes de diferentes campos como: el de la Psicomotricidad, la disciplina Danza Expresión Corporal, elementos de técnicas de Danza Contemporánea, tanto como del campo de las Danzas Folklóricas (estas últimas incluidas como un estilo más en Danza, e incorporadas a partir del aprendizaje y la recreación de diseños coreográficos de diferentes danzas, su contextualización histórico-socio-cultural, tanto como la utilización de elementos propios para la composición coreográfica).

Si bien se reconoce la presencia de ejes, como en la etapa curricular anterior, estos lineamientos amplían y profundizan el por qué y para qué del arte en la escuela desde una perspectiva de conocimiento específico y como derecho de acceso al campo de la cultura, siendo acompañado por un amplio desarrollo epistemológico y por políticas de impacto en el ámbito escolar.

\subsubsection{Danza disciplina/lenguaje desde una perspectiva cognitivista del campo artístico (2018)}

Como revisión y actualización de los documentos anteriores, al amparo de la ley de educación provincial $\mathrm{N}^{\circ} 13.688$ y en articulación con los Núcleos de Aprendizaje Prioritarios (NAP) ${ }^{5}$, se presentan nuevos lineamientos curriculares para la Educación Artística en el nivel primario dentro de un único Diseño: el Diseño curricular para la educación primaria: primer ciclo y segundo ciclo, del año 2018.

Documento que da continuidad a la concepción de un a área conformada a partir de cuatro Lenguajes/disciplinas (Música, Plástica Visual, Teatro y Danza), pero presentada desde una perspectiva cognitivista, que entiende que la educación artística:

Implica construir y acrecentar las competencias específicas de ese campo de conocimiento que, como todo campo particular, tiene un objeto de estudio, que es el arte en tanto proceso relacional y situacional, un lenguaje, que es el simbólico, y un método, que es el relacional e intersubjetivo en el marco de un paradigma de la complejidad (DISEÑO CURRICULAR PARA EDUCACIÓN PRIMARIA, 2018, p. 312).

\footnotetext{
5 Contenidos y estructuras prioritarias elaboradas a nivel nacional como referencia para las diferentes provincias del país.
}

Cadernos Cajuína, v. 6, n. 4, 2021, p. 156-179. 
Proponiendo como plataforma común a todos los lenguajes artísticos las nociones de: espacio, tiempo, subjetividad y relato, como ejes estructurantes, considerando que el abordaje de puntos en común puede favorecer el tránsito de un año a otro dentro del nivel primario.

Se prescribe que "en el Diseño Curricular del área, deben trabajarse desde una mirada que posibilite la articulación con estos primeros cuatro ejes: espacio; tiempo; subjetividad; relato, a los que se podrán sumar otras que atraviesen los lenguajes/disciplinas” (p. 313).

Si bien estos ejes no se ven reflejados de manera explícita dentro de los contenidos de cada una de las disciplinas artísticas, las referencias sobre ellos son las siguientes:

Espacio: "Espacios reales, espacios virtuales, espacios sociales, creación de espacios imaginarios, con diferentes características (llenos/vacíos), con indicadores (adelante/atrás), posibles de intervención, con modos de habitabilidad, entre otros, son conceptos que pueden construirse desde cualquiera de los lenguajes/disciplinas artísticas (...)” (p. 313).

Tiempo: “(...) problematizar con cuestiones relacionadas a temas como: tiempo real, tiempo relativo, temporalidades subjetivas, pasado, presente y futuro, mediciones del tiempo: años, horas, minutos, segundos, duración, Histórica (con mayúscula), tiempo mítico, etc.” (p. 313).

Subjetividad: "Podemos incluir aquí temas relacionados a la identidad, lo subjetivo, la(s) historia(s) (con minúscula), los vínculos, las relaciones, el gesto, el comportamiento, lo vivencial, el Otro, los roles, la alteridad, entre otros"(p. 314).

Relato: "Este apartado se focaliza en los modos particulares de la construcción discursiva de sentidos (Representativo, metafórico, poético, ficcional, entre otros)” “(...) indagar aquí en la impronta subjetiva de las narrativas que elabora el sujeto hacedor" (p. 314).

En este marco curricular los contenidos de la Danza se prescriben por nivel y por año a partir de bloques de contenidos.

Para el primer ciclo $\left(1^{\circ}, 2^{\circ}\right.$ y $3^{\mathrm{a}}$ año $)$ se priorizan tres grandes bloques bajo los nombres: elementos del Lenguaje de la danza; organización y contextualización del movimiento; y composición y producción coreográfica.

Un desarrollo con especial acento en el cuerpo y su relación con el movimiento, su registro postural y su alineación, y el espacio, en una propuesta que se presenta desde lo más 
introductorio en los elementos de la danza hacia la improvisación, la interpretación y producción gradualmente.

Relación que también puede verse en las situaciones de enseñanza sugeridas para cada año, que va desde los elementos vinculados principalmente con el eje postural, como el caso de la alineación de la columna, pasando por la relación cuerpo-espacio y por último una propuesta en torno al movimiento, a partir de la experimentación e improvisación (pasando de primero a tercer ciclo).

Por su parte para el segundo ciclo $\left(4^{\circ}, 5^{\circ}\right.$ y $6^{\circ}$ año), los bloques son: conceptualización de los componentes del lenguaje; interacción para la composición, y análisis y producción coreográfica.

Si bien se incluyen contenidos similares a los de primer ciclo como colocación del cuerpo, las relaciones con el espacio y el movimiento desde la Danza, se incluye la conceptualización de los elementos a los que se les suma la interpretación, la creación, el análisis y la creación coreográfica. Por otra parte, se destaca la dimensión de la danza como patrimonio cultural y la producción de discursos corporales. En este último aspecto, los contenidos abordan la dimensión escénica de la danza, desde el reconocimiento, reproducción de diseños y estilos propios de determinadas danzas (entre ellas, las danzas folklóricas), tanto como la creación de composiciones propias.

Respecto de las danzas folklóricas, y en vínculo con todo el recorrido que hemos realizado desde la etapa primera, no hay mención a danzas específicas, sino contenidos que proponen el abordaje de trayectorias, diseños y argumentos de diferentes danzas folklóricas, como figuras comunes e improvisaciones, experimentaciones de los diferentes roles en las danzas, reconocimiento de contexto de origen de los estilos y las relaciones con los contextos de la escuela.

Por último resulta necesario aclarar que si bien la perspectiva cognitivista es mencionada en el Diseño curricular, y en relación a ello se sostiene la consideración del arte como proceso relacional y situacional, tanto como una orientación en el modo de organizar los contenidos (conceptos, modos de conocer, indicador de avance), dicha posición es desarrollada en este periodo curricular a partir de cuatro documentos complementarios, que si bien no fueron abordadas en este artículo, resulta importante mencionarlos: Educación Artística 1. La planificación como berramienta para una Educación Artística generadora de saberes; Educación Artística 2. El Aprendizaje basado en Proyectos en el área de Educación Artística; Educación Artística 3. La secuenciación didáctica en el 
proceso cognitivo artístico Primer Ciclo; y Educación Artística 4. La secuenciación didáctica en el proceso cognitivo artístico Segundo Ciclo.

\subsection{Enseñar Danza. Voces de educadoras y educadores.}

Luego de haber mapeado e interpelado diferentes lineamientos curriculares de la enseñanza de la Danza en el nivel primario de la provincia, en esta apartado se establecen, a modo provisional y en relación al IV Simpósio nacional y el I Simpósio internacional de Infância, Educação e Teoría Crítica, diálogos con educadoras y educadores sobre qué se enseña cuándo se enseñanza danza y cuáles son sus sentidos prioritarios.

Con preguntas tales como: ¿Cuáles son los sentidos actuales de la enseñanza de la Danza en la educación de las infancias? ¿Cuál es tu posición sobre el por qué y para qué de la enseñanza de la danza en el contexto escolar? y ¿Qué impacto tuvo el contexto de Covid-19 en la enseñanza en general y en la enseñanza de la danza en particular?, se establecen los primeros vínculos con educadoras/educadores de Danza que trabajan en el nivel inicial, nivel primario y terciario de la provincia de Buenos Aires ${ }^{6}$, buscando complementar la mirada sobre la perspectiva contemporánea de su enseñanza y el impacto del contexto de pandemia.

A los fines de este trabajo se agrupan, de manera provisoria, las principales convergencias al momento de explicitar: los sentidos de la danza en la escuela, los contenidos educativos priorizados, y las reflexiones de las y los educadoras y educadores sobre el impacto de contexto COVID-19 en la enseñanza.

\section{3. 1. Por qué, para qué, y cómo se enseña de Danza en el nivel inicial y primario}

En el nivel inicial se trabaja muchísimo pero muchísimo lo corporal, tenés que poner el cuerpo mediante los chicos, mediante los docentes, mediante los padres a la hora de estar en un acto o lo que fuere, eso es a modo personal, y creo que es muy valedero el vínculo con los niños.

Y en el nivel primario creo que la danza como como eje primordial sigue los mismos lineamientos que en el nivel inicial, por lo menos en primer ciclo, en primero, segundo y tercer año, el cuerpo está a la vista de todo, creo que podemos desarrollar las capacidades de todos los nenes mediante los movimientos y también ubicarlos en un lugar y espacio y nivel donde puedan desenvolverse (Bailarín y profesor de Danzas Folklóricas Argentinas, entrevista realizada en el mes septiembre del 2020).

\footnotetext{
6 Resulta necesario aclarar que este apartado se elaboró a partir, principalmente, de cuatro entrevistas realizadas a educadoras y educadores formados en el campo de la Danza Expresión Corporal y en el campo de las Danzas Tradicionales Argentinas en los meses de septiembre y octubre del año 2020.
} 
En lo que es Nivel inicial por ejemplo yo intento, en los tres años, ir desarrollando todo lo que tiene que ver con partes del cuerpo, con forma básica de locomoción, con imágenes reproductivas, evocativas, para memorizar, para copiar, para improvisar con lo que es el movimiento y la quietud también, y después en lo que es primaria continuo con todo eso pero además le agrego o tengo más presente todo lo espacial, todo lo que implica también las nociones espaciales, y las trayectorias, y los diseños, las lateralidades, la derecha la izquierda, y la sumatoria de personas también en la forma en la que pueda desarrollar diferentes contenidos quizás de a dos, de a tres de a cuatro, de a cinco, ir sumando, ir complejizándolo también en ese sentido.

Para mí se tiene que enseñar danza porque nos ayuda a conocer mejor nuestro propio cuerpo (...) Y además sirve bueno sirve para romper también con un montón de estructuras que todavía están muy fijas en la escuela, ya poder...no se...modificar el espacio áulico para poder hacer otro tipo de materia me parece que resulta súper interesante a nivel estudiantes. Poder también modificar muchas veces el espacio, en el caso mío a veces lo hago en el aula, a veces me voy al SUM, a veces me voy al patio, creo que eso de poder tener una disciplina con aula itinerante por decirlo de alguna manera, también me parece que suma a la parte educativa (Bailarín y Profesor de Danzas Folklóricas Argentinas y de Danza Expresión Corporal, entrevista realizada entre los meses de septiembre y octubre del 2020).

Para ofrecer más formas de expresarse, de comunicarse y de vincularse desde el cuerpo y el movimiento $(\ldots)$

En el Jardín considero que brindar ese espacio es ofrecerles un momento de exploración de sus propios movimientos y potenciar, a su vez, esos descubrimientos tomando los emergentes que surjan para que ellos y ellas mismas puedan darse cuenta del momento vivido en el jardín

(En primaria) Se enseña para que incorporen y conozcan un lenguaje artístico relacionado al cuerpo y el movimiento. Dentro de la currícula hay muchos contenidos que incluyen otros aspectos donde involucran al cuerpo. Por ejemplo, experiencias con el espacio, con objetos auxiliares, con la música, con imágenes, entre otros. En este nivel es importante también comenzar con el trabajo en equipo o grupos. Poder escucharse, mirarse, ponerse de acuerdo y que sepan que el final será un hecho artístico creado a partir de su trabajo colectivo. (Bailarina, Danza movimiento terapenta, Profesora de Danza Expresión Corporal, entrevista realizada en septiembre de 2020).

Desde el mismo Diseño uno puede tener o saber cuál es el objetivo de la enseñanza de la danza, o del movimiento o del conocimiento del cuerpo en los niños, desde mi perspectiva puedo decir que lo que le permite en el nivel inicial, como también en el nivel nivel primario depende desde que edad empiezan a tener este primer contacto con el movimiento, los ayuda a poder desenvolverse en el mundo exterior, en la vida, ya sea en la escuela, en sus casas, el poder relacionarse, comunicarse a través del movimiento desde el cuerpo, poder recepcionar y percibir desde otras formas conocimientos también (...) Yo priorizo sobre todo el conocimiento del cuerpo, en aspectos generales y particulares, ese conocimiento del cuerpo en relación con el espacio, la comunicación con el otro, la comunicación en diferentes aspectos o sea desde el 
cuidado, desde el respeto. (Bailarina y Profesora de Danza Expresión Corporal, entrevista realizada en los meses de septiembre y octubre del 2020)

Como reflejan los relatos de educadoras y educadores hay una fuerte centralidad del cuerpo y lo corporal en la enseñanza de la Danza, no solo en las propuestas educativas para niños y niñas, sino en el involucramiento del docente en ese proceso. Por otro lado, se incluye la continuidad necesaria entre los niveles escolares y las referencias a los contenidos curriculares.

Se subrayan los vínculos con el área de la recepción, la comunicación y la expresión a partir de diferentes procedimientos con imágenes, música, objetos, en relación al espacio y a la propuesta de exploraciones, se destacan los trabajos individuales tanto como los grupales y la dimensión artística.

Por otra parte, se singulariza la posibilidad de habitar y usar el aula de clases comúnmente con bancos, sillas, pizarrones- de otras maneras, e incluso mudar el aula de danza, usar otros espacios escolares como el patio, los pasillos, salones de usos múltiples.

De este modo la Danza como espacio de educación artística debe, según educadoras y educadores, priorizar la educación del cuerpo, las dimensiones de cuidado, respeto, tanto como las dimensiones comunicativas, expresivas y lúdicas.

\subsubsection{Legitimidad de un campo de enseñanza}

A partir de las diferentes entrevistas realizadas es posible recuperar un núcleo de problemas que tiene que ver con el reconocimiento de la enseñanza de la Danza como un saber valorado y legitimado.

Si bien, tal como fue presentado, dentro las leyes educativas vigentes (nacionales y provinciales) la Educación Artística es reconocida como campo socialmente reconocido, valorado y como un derecho de acceso a la cultura, en palabras de los docentes queda aún un largo camino por recorrer en las instituciones escolares, dado que su consideración varia significativamente en relación al tipo de escuela y al contexto en el que se enseñe.

Yo creo que todavía al lenguaje artístico le falta mucho para que se lo considere como un lenguaje de conocimiento, o sea son muy pocas las instituciones o los directivos, en sí son los directivos, donde realmente toman al lenguaje artístico, y acá puedo hablar en general no solamente de la 
danza, como un área de conocimiento que lo toman como para poder complementar el conocimiento desde las otras áreas. Yo desde mi trabajo intento siempre conectarme con las maestras para poder saber qué es lo que va a entraban a trabajar y de esa manera poder complementar sus conocimientos. Así por ejemplo si trabajan con o en referencia en ciencias naturales a animales de diferentes ambientes acuáticos, terrestres, aéreos, bueno poder trabajar y diferenciar las calidades de movimiento según el tipo de... o la forma de trasladarse por el espacio, según el animal seleccionado, no?, entonces ahí está complementando el conocimiento que ellos ven desde otra mirada nosotros lo vemos desde el cuerpo, desde el movimiento, eh... pero bueno también se sigue sosteniendo, no en todas obviamente no todas en las instituciones, pero se sigue sosteniendo esto de que es un área más recreativa, un área más de disfrute y no de saber. (Bailarina y Profesora de Danza Expresión Corporal, entrevista realizada en los meses septiembre y octubre del 2020).

(Respuesta a la pregunta por expectativas institucionales)

Si. Los directivos de las escuelas donde actualmente formo parte, siempre están convocando a los docentes de artística para trabajar en equipo por proyecto con las docentes de las aulas. El propósito es que podamos ofrecer a los y las estudiantes otras formas de aprender un mismo tema. Otros, podrían ser en fechas puntuales como el aniversario de la escuela o semana de las artes donde siempre se convoca para idear alguna forma de festejo artística.

En cambio, tuve la experiencia en otra escuela donde los dueños ponían al Arte dentro de la práctica educativa, como una pérdida de tiempo.

Yo me pregunto entonces, también respondiendo a la pregunta anterior, para no seguir cayendo en miradas hegemónicas, ¿Por qué se enseña matemáticas? ¿y lengua? Es nuestro deber como docentes de la danza legitimar nuestro espacio dentro del ámbito educativo. Es tan importante como el resto de las materias, y poner en claro a su vez que no solo tenemos que participar en los actos o festejos, sino también crear proyectos propios y poder buscar el momento para visibilizar el trabajo realizado. (Bailarina, Danza movimiento terapeuta, Profesora de Danza Expresión Corporal, entrevista realizada en el mes de septiembre de 2020).

De este modo las reflexiones evidencian la necesidad de sostener y defender un espacio, que si bien es valorado desde las dimensiones prescriptivas, tiene un lago camino por recorrer, dado que su reconocimiento varía en relación a los marcos institucionales en los que se inscribe.

\subsubsection{Impacto del contexto COVID-19 en la enseñanza de la Danza}

El contexto del Aislamiento Social Preventivo y Obligatorio, a causa del COVID-19, tuvo un gran impacto en el sistema educativo argentino. La suspensión de clases presenciales y la construcción de redes y de recursos para sostener la escuela en un escenario tan complejo como diverso, evidencio una desigualdad que preexistía, "la pandemia encontró a los sistemas educativos latinoamericanos heridos o mortalmente dañados" (PUIGGRÓS, 2020, p. 33).

La escuela, tal y como la conocíamos, muto de lugar, de forma, y se transformo en modos de relaciones diversas con la finalidad de establecer la continuidad pedagógica en un contexto que puso en crisis, y en debate, no solo los sentidos de la escuela sino las formas y las prioridades de educar en emergencia sanitaria. 
En este marco, de clases a distancia, de modalidades y de soportes diversos, la enseñanza de la Danza también se vio modificada. Transcribimos, como línea inaugural y para seguir pensando, algunas de las reflexiones sobre el impacto de este en su enseñanza, específicamente sobre el período de marzo y octubre del año 2020.

Dentro de mi experiencia y por lo que uno charla con sus colegas, el impacto es desigual. Como sabemos, la virtualidad no es democrática. No todos tienen el alcance a tener un dispositivo para conectarse o una buena señal de internet. En mi caso, por ejemplo, tenemos una sola computadora y ambos tenemos que trabajar diariamente con ella (...) Todas las enseñanzas se vieron afectadas por que la única salida para la continuidad pedagógica fue la virtualidad. Entonces cada docente tuvo que tomar sus propias estrategias y formas de enseñar desde ahí. Sabemos que no es lo mismo incentivar y motivar estando juntos y juntas en un mismo espacio y tiempo que haciéndolo a través de un video.

Se puede sostener un tiempo, pero no tanto como el que estamos atravesando donde escuchas diariamente, "están cansados". Y si, es así, y se entiende, pero nuestro rol es continuar y continuar explorando nuevas formas de llegar a ellos. Escuchar, tomar las críticas, modificar y contener. Aunque admito que se hace muy difícil. La dinámica familiar cambio muchísimo desde el mes de marzo.

Grabar cuando los niños duermen la siesta, realizar las actividades con ellos que les envían del jardín, conectarse a su zoom, turnarse con mi compañero para estar con ellos mientras él o yo damos una clase virtual. Y así, muchas situaciones más... (Bailarina, Danza movimiento terapeuta, Profesora de Danza Expresión Corporal, entrevista realizada en el mes de septiembre de 2020).

El COVID en la enseñanza en general, tuvo todo el impacto posible. Yo creo que se vio afectado sobre en el tema de la tecnología, esto del alcance a la tecnología en todos los sectores. Está muy sectorizado quién es el que puede tener la enseñanza más fácil que otros, de igual manera eh... viste que en el diseño este nuevo de primaria y bueno el de inicial también aparecía la incorporación de las tics, es como que nos obligó de cierta manera a aplicar esa incorporación de las tic pero con la falencia o con la falta de conocimiento que tenemos todos los docentes, hay algunos que tienen más conocimientos que otros, pero... y hay algunos que se han podido arreglar mejor que otros, lo que pasa es cómo aplicar esta tecnología para que sea realmente de conocimiento y a su vez poder atrás para atrapar, innovar, poder engancharlo, por decirlo de alguna manera, a los alumnos y sobre todo a las familias, más que nada en los niveles más chicos porque ahí simplemente tenes que atrapar con la propuesta a las familias y si a las familias le parece que es práctico, conciso, divertido y que lo pueden aplicar se lo van a mostrar a sus niños o niñas y entonces como medio complicado, y en la danza sobre todo que es en relación del movimiento también... si bien uno puede trabajar desde juegos más sencillos o sea uno lo que busca, también el pedido desde arriba fue esto de priorizar los contenidos a ver cuáles son los de los prioritarios para poder trabajar y también los contenidos que se puedan llegar a dar en este contexto y de este formato, entonces es como que en la danza es medio difícil porque uno trabaja desde el cuerpo, con el cuerpo y a veces hasta incentivando la búsqueda con el propio cuerpo, y entonces como medio complicado, yo por mi parte ofrecí un primer momento, fue uno se fue reinventando a medida que fue pasando también la cuarentena, entonces a principio fue como estimularlo de la escritura, o sea escribir el plan con la actividad para que los padres los llevan a cabo, lo mismo me pasaba con terciario, no dejaba de ser un seguimiento de ejercicios y no de 
búsqueda y explotación del movimiento, después comencé con la incorporación de videítos, de vídeos, yo ofreciéndoles también un baile como para que empiecen se atrapaen desde lo visual y que se engancha desde el movimiento y después de ahí empezar a proporcionar la actividad y después de receso invernal me pareció que el baile también llegaba a ser como muy agotador, no sé si baile, sino la duración de los vídeos, esto de que un vídeo dure cinco minutos puede llegar a cansar a los niños para que los puedan ver y después hacer la actividad, entonces como que fui más concreta y explicar de manera sencilla cómo llevarlo a cabo, la cuestión es que en verdad eh yo transmito a la familia de qué manera deberían jugar con sus niños o niñas o de qué manera incentivarlos cuando en verdad ellos nunca aprendieron porque no son docentes danza ni docentes en general, entonces es lo que digo o sea me parece que lo que se hace es un seguimiento de una serie de ejercicios que uno proporciona o sea una serie de ejercicios que uno invita a explorar. (Bailarina y Profesora de Danza Expresión Corporal, entrevista realizada en el mes septiembre del 2020)

Para mi tuvo un impacto trascendental, me parece que lo que hace este virus es desmantelar lo desigual que es la forma de aprendizaje, el acceso a la educación que tenemos, es algo que de alguna manera esta naturalizado, me parece que realmente es imposible trasladar el tiempo de la escuela a las casas, no todas las personas tienen la misma conexión la misma cantidad de dispositivos en su casa o una por persona para poder trabajar cosas distintas (...) Yo la estoy trabajando a la danza desde un lugar mucho más creativo si que quiere desarrollando desde lo lúdico que sea más atractivo y que se disfrute porque la verdad no tiene ninguna lógica para mí.

(...)Las principales problemáticas y desafíos tienen que ver con la cuestión de conectividad. Nosotros no estamos haciendo educación a distancia estamos haciendo educación en emergencia sanitaria (Bailarín y Profesor de Danzas Folklóricas Argentinas y de Danza Expresión Corporal, entrevista realizada entre los meses de septiembre y octubre del 2020).

Es posible decir que el impacto del COVID-19, al menos desde las voces de las y los educadoras/res, visibilizo un acceso desigual a la tecnología, la dificultad de sostener la continuidad pedagógica frente a un contexto que no solo interpelo y traspaso límites entre aquello que era del orden de lo privado: la familia, y de lo público: la escuela, sino que interpelo los propios modos de organización familiar de alumnas/os como de docentes.

Por otra parte vuelve a ponerse sobre arena de debate cuál es la importancia de la educación artística, de la Danza, y si ésta como campo de conocimiento resulta ser un contenido prioritario o accesorio en un contexto que sacude los pilares mismos de la escolarización.

El caso particular de la enseñanza de la Danza se evidencio entonces: desigualdad socioeconómica en el acceso y en los recursos materiales de cada hogar para sostener una escolaridad virtual; la centralidad y la necesidad de involucramiento de las familias como sostén de nuevas modalidades de enseñanza: el escaso cumplimiento de las actividades como contracara, por un lado del agotamiento y sobrecarga de trabajos mediados por pantallas, y por el otro de la jerarquización de contenidos/conocimientos en y desde lo escolar, donde materias como 
prácticas el lenguaje, matemáticas, por mencionar algunas, fueron priorizadas por sobre las demás; y un educador/ra dividido/a entre la educación de su propia familia y su rol profesional. Fusión problemática de los espacios casa-trabajo.

Por otra parte, los desafíos de su enseñanza en un contexto de aislamiento social fueron: priorizar una enseñanza que brinde herramientas para niños/ñas reconozcan su propio cuerpo, en sus aspectos sensible, comunicativo y creativo, aunque esta sea mediada por tecnologías; promover una educación del movimiento a través de lo lúdico y del trabajo con elementos del hogar; propiciar propuestas de actividades de Danza que pudieran ser realizadas y compartidas en familia; establecer relaciones con expresiones socioculturales a partir de imágenes, videos, textos, canciones, entre otras.

\section{CONCLUSIONES}

Este artículo se propuso recorrer dimensiones históricas y contemporáneas de la Danza en la escuela de la provincia de Buenos Aires, para ello fue necesario recurrir a investigaciones previas, basadas centralmente en análisis de documentos prescriptivos, y ponerlos en diálogo con relatos y reflexiones de educadoras y educadores del campo de la danza en el nivel primario.

El primer apartado permitió reconocer el ingreso de las danzas folklóricas como una dimensión presente en la escuela mucho antes de ser un espacio curricular específico. Comparar las primeras dos perspectivas: una desde el área del Folklóre (1983, 1993), y la otra desde el campo de la Expresión Corporal (1995-1999), indagando y desarrollando sus contextos de producción.

El segundo desplegó centralmente consideraciones de la Educación Artística en el sistema argentino a partir de las leyes educativas vigentes, la nacional y la provincial, para abordar el impacto de dichos lineamientos en las publicaciones curriculares específicas. Fueron desarrolladas las consideraciones de la Danza desde dos grandes marcos curriculares: la Danza desde una perspectiva de acceso y derecho a la cultura en el reconocimiento de paradigmas artísticoestéticos diversos (2008), y el desarrollo prescriptivo-pedagógico de la Danza desde una consideración cognitiva del campo artístico.

Por último, se dio voz a las posiciones y las reflexiones de educadoras y educadores de Danza buscando ampliar la mirada desde las prescripciones a las realidades áulicas. Diálogos que evidenciaron: la centralidad y la importancia del cuerpo y de lo corporal en la enseñanza de la 
danza, en un cruce con dimensiones como la recepción, la comunicación y la expresión; el rol relegado del campo artístico en algunas de las instituciones educativas, como la disputa por la consolidación y su reconocimiento como saber específico en el contexto escolar; por último se analizó el impacto del contexto de emergencia sanitaria por el avance del COVID-19 en la región.

Si bien este trabajo se propuso abordar la educación de la Danza, en un cruce entre los lineamientos curriculares y las prácticas educativas, son muchas las líneas para seguir pensando su enseñanza, tanto como el impacto que los diferentes contextos socio-culturales y las consideraciones institucionales tienen dicha práctica educativa.

\section{REFERENCIAS}

ARGENTINA. Ley Nacional de Educación n 24.195, 1993.

ARGENTINA. Ley Nacional de Educación nº 26. 206, 2006.

ARGENTINA. Ley Provincial de Educación n ¹1.612, 1994/1995.

ARGENTINA. Ley Provincial de Educación nº 13.688, 2007.

BELINCHE, Daniel. Arte, poética y educación. La Plata: el autor, 2011.

BLACHE, Martha, \& DUPEY, Ana. María. Itinerarios de los estudios folklóricos en la Argentina. Revista Relaciones de la Sociedad Argentina de Antropología, T. 32, p. 299-317, 2007. Disponible en http://sedici.unlp.edu.ar/handle/10915/21042

HIROSE, María Belén. El movimiento institucionalizado: Danzas folklóricas, la profesionalización de su enseñanza. Revista del Museo de Antropología RMA v. 3, n. 1, p. 187-194, 2010. Disponible en https://revistas.unc.edu.ar/index.php/antropologia/article/view/5460

HIROSE, María Belén. Bailando las palabras: los documentos. En M. J. Carozzi (Org.). Las Palabras y los Pasos. Etnografías de la danza en la ciudad. Buenos Aires: Editorial GORLA, 2011, p. 82-115.

KALMAR, Deborah. Qué es la Expresión Corporal. A partir de la corriente de trabajo creada por Patricia Stokoe. Buenos Aires: Lumen, 2005.

MERLOS, Lucía. Danza y Escuela. Perspectivas educativas en la provincia de Buenos Aires (1983-2018) [Tesis de Maestría] Universidad Nacional de La Plata, 2020. 
MUZZOPAPPA, Eva; VILLALTA, Carla. Los documentos como campo. Reflexiones teóricometodológicas sobre un enfoque etnográfico de archivos y documentos estatales. Revista

Colombiana de Antropología v. 47, n. 1, 13-42, ene/jun. 2011.

PUIGGRÓS, Adriana. Balance del estado de la educación, en épocas de pandemia en América Latina: el caso de Argentina. En: DUSSEL, Inés (Org.).Pensar la educación de pandemia: entre la emergencia, el compromiso y la espera. Buenos Aires: UNIPE, Editorial Universitaria, 2020, p. $33-42$.

PROVINCIA DE BUENOS AIRES. Anexo 1 de la Disposición N 31.La Plata: Dirección General de Escuelas y Cultura, La Plata, 1993.

PROVINCIA DE BUENOS AIRES. Diseño Curricular Educación Inicial Educación General Básica Tomo II. La Plata: Dirección General de Cultura y Educación, 1999.

PROVINCIA DE BUENOS AIRES. Diseño Curricular para la Educación Primaria. Primer Ciclo Volumen 1. La Plata: Dirección General de Cultura y Educación, 2008.

PROVINCIA DE BUENOS AIRES. Diseño Curricular para la Educación Primaria. Segundo Ciclo Volumen 1. La Plata: Dirección General de Cultura y Educación, 2008.

PROVINCIA DE BUENOS AIRES. Diseño Curricular para la Educación Primaria: primer ciclo y segundo ciclo. La Plata: Dirección General de Cultura y Educación, 2018.

PROVINCIA DE BUENOS AIRES. Lineamientos curriculares Educación Básica $1^{\circ}$ a $7^{\circ}$ Grado. La Plata: Dirección General de Escuelas y Cultura, 1986.

PROVINCIA DE BUENOS AIRES. Módulo 0. La Plata: Dirección General de Cultura y Educación, 1995.

PROVINCIA DE BUENOS AIRES. Resolución N³88, Anexo 1. La Plata: Ministerio de Educación y Cultura, 1983. 